\title{
FACTORS AFFECTING THE ADHERENCE TO AN ANTENATAL SCREENING PROGRAMME: AN EXPERIENCE WITH TOXOPLASMOSIS SCREENING IN FRANCE
}

\author{
C Cornu ${ }^{1}$, A Bissery $2,3,4$, C Malbos $^{5}$, R Garwig'5 ${\text { C } \text { Cocherel }^{5} \text {, R Ecochard }}^{2,3,4}$, F Peyron ${ }^{6}$, M Wallon \\ (martine.wallon@chu-lyon.fr) 6
}

1.Institut national de la santé et de la recherche médicale (National institute for health and medical research, INSERM)

CIC201, Hospices Civils de Lyon, Clinical Pharmacology Unit, Lyon, France

2. Hospices Civils de Lyon, Department of biostatistics, Lyon, France

3. Centre national de la recherche scientifique (National centre of scientific research, CNRS), UMR 5558, Villeurbanne, France

4. University Claude Bernard, Laboratoire Biostatistique Santé, Lyon, France

5. Union Régionale des Caisses d'Assurance Maladie (Regional Union of Health Insurance Services, URCAM) Rhône-Alpes,

Lyon, France

6. Hospices Civils de Lyon, Parasitology Department, Hôpital de la Croix-Rousse, Lyon, Francel

Monthly serological testing is mandatory in France for pregnant women not immune to toxoplasmosis. We assessed for the first time the adherence to this national programme, using data from antenatal tests for Toxoplasma antibodies collected by the Union of Health Insurance Services in the French Rhone-Alpes region. Data from 34,290 pregnancies was analysed. The first test was done late in $25 \%$ of women $(8,430)$. Women had on average 5.7 tests during pregnancy, only 40 percent $(13,774)$ were tested seven or more times as recommended. Young women were more likely to have a late first test, but age did not significantly influence regularity and number of tests. Free medical coverage favoured a late first test, fewer tests and longer between-test intervals. An early first test did not affect test numbers or between-test intervals. A re-useable prescription for several tests was associated with better adherence. Prescription by general practitioners was associated with an earlier first test, but fewer tests and longer between-test intervals. When prescribing physician(s) included a gynaecologist, the first test was more likely to be behind schedule, but the overall number of tests was higher and between-test intervals shorter. Because data was collected through private laboratories, our conclusions apply to the majority of French patients who need to schedule a separate visit for blood testing after prescription.

\section{Introduction}

Congenital Toxoplasma infection arises in 25\% of acute maternal infections during pregnancy. The consequences for the foetus can be severe, most often ophthalmologic or affecting neurodevelopment [1,2], and are diagnosed immediately, at birth or later during childhood or adulthood [2]. In an attempt to decrease the number of children with severe infections, several countries have implemented mandatory or recommended antenatal testing programmes in order to promptly recognise and treat acute maternal Toxoplasma infections. In France, a antenatal screening programme was implemented in 1978. It has included, since 1985, detection of antibodies against Toxoplasma before the end of the 12th week of gestation - the official deadline for registering a pregnancy - followed, since 1992, by a monthly testing until the time of delivery for patients who are not immune. There is a recommended minimum of seven tests. The preventive impact of this programme remains to be proven. Adherence to this programme is also relevant when debating its effectiveness, but has never been addressed. We present here an analysis of the adherence to the French screening programme for congenital toxoplasmosis. It is specifically targeted to women who are tested in private laboratories, which is common for outpatients in France. This feature of the French health care system requires an obligation on the patients' part to schedule the different appointments for blood sampling. Patients need to pay for the tests, but will be reimbursed, provided that the tests were prescribed by a physician (general practitioner (GP) or any specialist doctor) or a registered midwife.

The goals of our study were to assess adherence to the programme and to identify reasons for poor adherence, in order to develop a communication strategy specifically targeted to pregnant women and their physicians.

\section{Patients and methods}

\section{Available data}

We used data collected for reimbursement purposes by the Regional Union of Health Insurance Services (URCAM) of the French Rhone-Alpes region. They record the biological analyses performed at private laboratories and reimbursed for the part of the population ( $86 \%$ ) insured by the main health insurance system. The national coding system for biological analyses allows differentiation between the first antenatal test, intended to determine the patient's immunity, and subsequent follow-up tests required to exclude later seroconversion. For each test, dates of issue of prescription and date of blood sampling were available, along with information on the professional who prescribed the test (GP, obstetrician-gynaecologist, other specialist or registered midwife, public or private practice). Patient data included age at delivery, dates of conception and 
delivery, whether she delivered in a private or public hospital, and whether she was fully covered by the national health service - free medical coverage (FMC) being attributed to low income.

\section{Study population}

We selected all women living in the Rhone-Alpes Region who delivered between 1 July 2002 and 30 June 2003 and for whom at least two tests for Toxoplasma infection were reimbursed, including one follow-up test. The aim was to select women who were not immune to toxoplasmosis and who were supposed to undergo the mandatory monthly testing schedule. Data was extracted anonymously by the URCAM statistics department and analysed by the biostatistics department of the Lyon teaching hospital.

\section{Criteria}

The first studied criterion was whether or not the first test had been performed within the first 12 weeks of pregnancy. Factors included in the analysis were: age, FMC, delivery in a public or private hospital, profile and type of practice of prescribing physician.

Two additional follow-up criteria were the mean number of tests throughout pregnancy and the mean time interval (in days) between two consecutive tests.

\section{Statistical methods}

Continuous variables were described with mean, median, standard deviation (SD), minimum and maximum. The mean between-test interval for each patient was calculated as the mean of the intervals between two consecutive tests uncorrected for potential correlation between intervals. Binary variables were described with number and percentage. Association between outcome and independent predictors was studied through different types of regression models: Logistic regression was used for the binary dependant variable "late first test". All variables linked to the women (age, FMC, delivery in a public or private hospital) as well as the profile of the prescribing physician(s) during pregnancy

\section{F I G U R E}

Exclusions from the data file with justification, antenatal toxoplasmosis screening programme, France, 2002/03

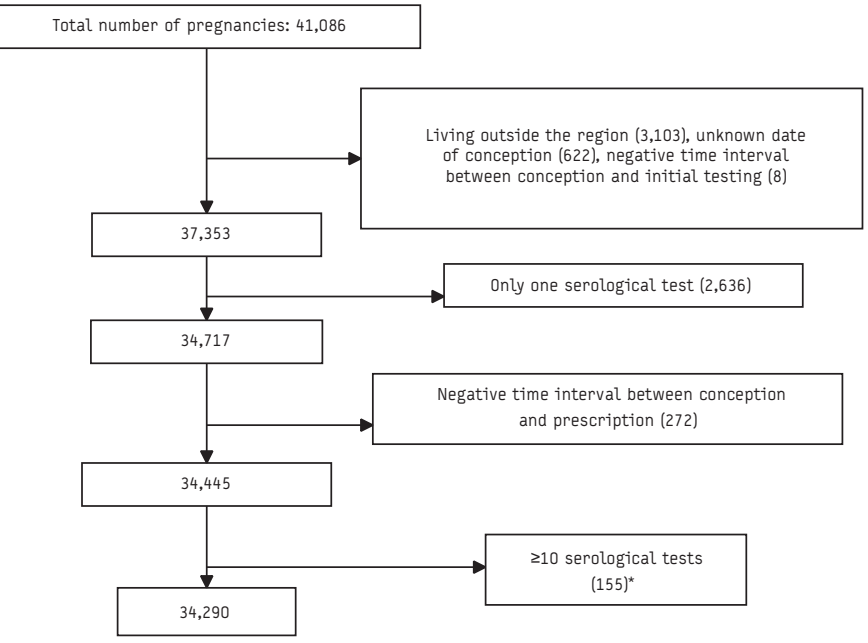

*Women who had more than ten tests reimbursed were excluded because this could suggest occurrence of a seroconversion. were divided into four categories - GP(s) only, obstetriciangynaecologist(s) only, GP(s) plus obstetrician-gynaecologist(s), other specialists (including registered midwives) - and entered into the model.

For the other two criteria, three further predictors linked to the first test were added to the previous set of variables: "tests done on schedule (yes/no)", "time interval between prescription and testing" and "prescription for the initial test re-used on at least one follow-up test (yes/no)". Poisson regression was used for the ordinal variable "number of tests", with the number of weeks of pregnancy as offset. All independent covariates tested individually reached statistical significance $(p<0.01)$. except the items related to the patients' first test, which were nevertheless considered as important and retained in the final model.

A linear regression model was run for the continuous variable "time interval between two consecutive tests". All variables were individually associated with a $p$ value under 0.01 and kept in the final model, except for the re-use of prescription. Nevertheless, this factor was considered to be important and retained in the model. The effect of age was modelled as a linear relation after verifying several multivariable fractional polynomials models.

Statistical significance was accepted for $p<0.05$. Analyses were performed using STATA® release 9 (Stata Corporation 2005, College Station, Texas, United States).

\section{Results}

\section{Study population}

There were 41,086 deliveries during the study period. For 38,450 women, two Toxoplasma antibody tests, including at least one follow-up test, were reimbursed. After exclusion of 4,160 women, 34,290 remained in the final sample. The reasons for exclusion and their number are given in the Figure.

The characteristics of patients, prescribing physicians and tests are presented in Table 1.

The mean age of the women was 29.5 years; 1,086 women (3.17\%) were under 20 years-old and 467 (1.36\%) over 40 yearsold. Mean gestation was 37.6 weeks (SD 1.9). Most pregnancies lasted 37 weeks or more $(24,882 ; 72.6 \%)$, very few lasted less than 34 weeks $(1,164 ; 3.39 \%)$. A large proportion of women had one $(15,068 ; 43.9 \%)$ or two $(14,946 ; 43.6 \%)$ prescribing physician(s). The majority of women had all tests done in one $(26,588 ; 77.4 \%)$ or two laboratories $(6,599 ; 19.3 \%)$. Prescriptions for the first test were re-used for at least one more test by 2,832 $(8.26 \%)$ patients. For 512 women $(1.49 \%)$ there was a single prescription for the totality of the tests. The re-usable prescriptions were written by a GP for 707 (25.0\%) of the 2,832 women, by a obstetrician-gynaecologist for $2,083(73.6 \%)$, and by another specialist or a registered midwife for $37(1.31 \%)$. Since almost all prescribing physicians $(99.29 \%$ ) were in private practices, this co-variable was disregarded in the following analyses.

\section{Initial test}

The first test was prescribed on average at 8.3 weeks of gestation (median 7.1; SD 5.0; min 0, $\max 36.6$ ), in $60 \%$ of cases by a gynaecologist (Table 1 ). The mean time interval between prescription and testing was 7.9 days (median 3; SD 12.3, min 0 , max 178); it was longer in younger women $(p<0.0001)$, in women with FMC $(p<0.0001)$, and when the test was prescribed by an obstetrician-gynaecologist rather than by a GP $(p<0.0001)$. 
The first test was performed at 9.5 weeks of gestation on average (median 8.4; SD 5.4, min 0, max 37.6). It was performed within the recommended schedule (in the first 12 weeks of pregnancy) in $75.4 \%$ of cases $(25,860)$.

\section{T A B L E}

Characteristics of women, prescribing physicians and tests, antenatal toxoplasmosis screening programme, France, $2002 / 03$

\begin{tabular}{|l|c|}
\hline Characteristics & $\begin{array}{c}\text { Mean } \\
\text { (SD; min-max) }\end{array}$ \\
\hline Age of pregnant women & $29.5(4.9 ; 14-54)$ \\
\hline Length of pregnancy (weeks) & $37.6(1.9 ; 21-44)$ \\
\hline Number of prescribing physicians per patient & $1.7(0.74 ; 1-7)$ \\
\hline Number of prescriptions per pregnancy & $4.9(2.0 ; 1-9)$ \\
\hline Number of tests per pregnancy & $5.7(1.9 ; 2-9)$ \\
\hline Number of different laboratories used per pregnancy & $1.3(0.5 ; 1-6)$ \\
\hline Number of weeks between first and last test & $22.9(7.7 ; 0-38)$ \\
\hline & Number (\%) \\
\hline Free medical coverage & $3,319(9.7)$ \\
\hline Delivery in a public hospital & $23,537(67.6)$ \\
\hline Profile of physician who prescribed the first test & \\
\hline General practitioner & $13,431(39.2)$ \\
\hline Gynaecologist & $20,569(60.0)$ \\
\hline Other & $290(0.8)$ \\
\hline Profile of physician(s) who prescribed the follow-up tests & \\
\hline General practitioner(s) only & $6,596(19.2)$ \\
\hline Gynaecologist(s) only & $15,864(46.3)$ \\
\hline General practitioner(s) and gynaecologist(s) & $10,534(30.7)$ \\
\hline Other specialist(s) & $1,296(3.8)$ \\
\hline
\end{tabular}

SD: Standard deviation.
Independent predictors for a delayed first test were: FMC (odds ratio (OR) 2.39; 95\% confidence interval $(\mathrm{Cl})$ [2.22-2.58]), age (OR $1.0395 \% \mathrm{Cl}$ [1.02-1.04] per year younger) and prescription by a obstetrician-gynaecologist (OR $1.2995 \% \mathrm{Cl}$ [1.22-1.36]) or another specialist (OR $1.6895 \% \mathrm{Cl}[1.30-2.18]$ ) rather than a GP.

\section{Test number and frequency}

Number of tests

Women were tested on average 5.7 times (median 6; SD 1.9, min 2, max 9), an average adherence rate of $81 \%$ (see Table 1). 40.2 percent $(13,774$ women) were tested seven or more times, as recommended.

Independent predictors for a lower number of tests are summarised in Table 2: FMC $(p<0.0001)$ had the greatest impact (incidence-rate ratio $(\mathrm{IRR})=0.84 ; 95 \% \mathrm{Cl}$ [0.83-0.85], followed by delivery in a public hospital ( $p<0.0001), G P(s)$ only as prescribing physician $(s)(p<0.0001)$, a first test performed late $(p<0.0001)$, a long time after prescription $(p<0.0001)$, and a test done with a prescription that was not re-used $(p<0.001)$.

\section{Between-test intervals}

The mean between-test interval was 37.6 days (median 32.7; SD17.9; $\min 0, \max 229$ ). Eighty percent $(27,402)$ of women had at least one between-test interval exceeding 35 days, 22,954 women $(66.9 \%)$ had two or fewer intervals exceeding 35 days. The intervals were significantly longer in women who had FMC $(p<0.0001)$, delivered in a public hospital $(p<0.0001)$, had only GPs as prescribing physicians, had a late first test $(p<0.0001)$ or used multiple prescriptions (one per test) rather than a re-usable prescription $(p<0.001)$ (Table 2).

\section{Discussion}

The goals of our study were to determine compliance with the screening programme for toxoplasmosis in pregnant women tested in private laboratories and to identify predictors for non-compliance. Compliance was unsatisfactory, with a quarter of the participants doing the first test too late, $80 \%$ of participants having at least one

\section{T A B L E}

Effects of the characteristics of women, physicians and the first toxoplasmosis test on the number of tests and mean betweentest interval, antenatal screening programme, France, 2002/03

\begin{tabular}{|c|c|c|c|}
\hline & Reference & $\begin{array}{l}\text { Overall number of tests } \\
\text { Risk ratio for one additional test [ } 95 \% \mathrm{CI}]\end{array}$ & $\begin{array}{c}\text { Mean between-test interval (days) } \\
\text { Interval [ } 95 \% \mathrm{CI}]\end{array}$ \\
\hline \multicolumn{4}{|l|}{ Patient profile } \\
\hline Age of pregnant women & Per year older & $\mathrm{NS}^{*}$ & $\mathrm{NS}^{*}$ \\
\hline FMC & No FMC & $0.84[0.83 ; 0.86]$ & $6.02[5.4 ; 6.7]$ \\
\hline Delivery in private hospital & In public hospital & $1.04[1.03 ; 1.05]$ & $-0.45[-0.87 ;-0.03]$ \\
\hline \multicolumn{4}{|l|}{ Testing profile } \\
\hline First test late & Not late & $0.70[0.69 ; 0.71]$ & $-0.73[-1.2 ;-0.2]$ \\
\hline Interval between first test prescription and testing & Per 10 additional days & $0.995[0.994 ; 0.995]$ & $\mathrm{NS}^{*}$ \\
\hline First prescription re-used for at least one test & Prescription not re-used & $1.07[1.29 ; 1.47]$ & $-4.7[-5.4 ;-4.0]$ \\
\hline \multicolumn{4}{|l|}{ Profile of prescribing physician(s) } \\
\hline Gynaecologists(s) only & GP(s) only & $1.08[1.40 ; 1.57]$ & $-4.2[-4.7 ;-3.6]$ \\
\hline GP(s) + gynaecologist(s) & GP(s) only & $1.16[1.15 ; 1.18]$ & $-3.4[-3.9 ;-2.8]$ \\
\hline Other & GP(s) only & $1.19[1.16 ; 1.22]$ & $-4.3[-5.4 ;-3.2]$ \\
\hline
\end{tabular}

${ }^{\star}$ CI: confidence interval; FMC: free medical coverage; GP: general practitioner; NS: not significant. 
between-test interval exceeding 35 days and $60 \%$ of participants completing fewer than the recommended seven tests.

These findings were based on a large dataset collected from the Rhone Alpes population which represented $9.7 \%$ of the total French population and $9.3 \%$ of all births in 2003 [3]. It did not include women covered by the health care systems for agricultural or independent workers (14\% of the population), but we have no reason to assume that the testing behaviour should be different in that subset of the population. Women who were not tested at all were also disregarded in the study, but these patients, whose number are impossible to estimate, are likely to have such a different profile that they would require a specific study to understand the reasons why they are not included in standard care. We can not rule out the possibility of a small proportion of women having a test and forgetting to apply for reimbursement, but considering the large amount of data in our file, it is unlikely that they significantly modified our conclusions. The number of pregnancies in our study was indeed consistent with the 76,349 births registered for 2003 in the Rhone Alpes region [3] and the estimated regional seroprevalence for Toxoplasma infection of 36.1\% [4]. Furthermore, our data was in line with national estimates concerning mean age of pregnant women, rates of free medical coverage and of deliveries in a public hospital [5].

As no other study has been conducted since the French screening programme was implemented, it is unknown whether adherence has always been insufficient. Prenatal programmes for toxoplasmosis only exist in several other countries [6], although there are differences in the testing schedule and in how the sampling is organised Data on compliance, however, have only been reported in one Brazilian study, which also found adherence to screening to be insufficient [7].

Compliance affects cost and effectiveness of screening [8], but the consequences of the substandard compliance observed in our study are difficult to measure. The earlier a patient at risk (i.e. a pregnant woman who has no immunity against toxoplasmosis) is identified, the more do they benefit from information on how to avoid infection. Consequently, late testing should be associated with a higher incidence of maternal infections. However, this cannot be measured in the absence of a notification system. There is also uncertainty regarding the effectiveness of health education [9]. Having a late first test that is positive for anti-Toxoplasma IgG makes it more difficult for the biologist to determine whether the infection was acquired before or after the beginning of pregnancy. This uncertainty generates additional costs for complementary testing as well as anxiety for the future parents.

In the event of seroconversion, long intervals between tests prevent prompt treatment and should theoretically increase the number of infected children and severity of infection. A study done by the Systematic Review on Congenital Toxoplasmosis (SYROCOT) study group found weak evidence that treatment started within three weeks, compared to treatment started after eight weeks of seroconversion, reduces mother to child transmission, which indirectly suggests that compliance with monthly testing is important. However, the study failed to demonstrate the preventive effect of antenatal treatment on clinical manifestations of congenital infection [10]. Compliance will have to be taken into account in any controlled studies conducted on the benefit of antenatal treatment, as well as in any "real life" applications of their findings.
Several studies will be necessary to understand the reasons for the insufficient testing observed in this study. They will have to take into account the use of other prenatal care programmes and additional socio-demographic and economic variables. The role of insufficient patient knowledge on Toxoplasma infection and on its consequences for the foetus should also be investigated. Previous data on primary prevention of toxoplasmosis suggested that French women at risk tend to neglect precautions regarding food and hygiene [11-12]. Linking the number and timing of Toxoplasma tests with the patients' daily efforts to avoid infection could help us understand if, or how, both types of prevention interact.

Meanwhile, our study provides several possible directions for improving preventive programmes, particularly those that require patients to make appointments for repetitive examinations. These efforts should ideally be directed towards all actors involved.

Two factors were associated with patients. Receiving free medical coverage was independently associated with a late first test, and with fewer tests overall and longer between-test intervals, indicating continued insufficient access to the health care system or a persistent lack of awareness regarding screening, already widely reported for instance in the 2003 French National Perinatal Survey [5]. Younger patients were also more likely to have a late first test which possibly reflects a lower awareness of standard care offered during pregnancy and a higher proportion of unwanted or belatedly recognised pregnancies. Interestingly, age did not affect the overall number of tests or their regularity, suggesting that factors responsible for the delayed first test were somehow overcome.

Efforts should be made to reach out towards patients who have the least access to information, in order to inform them of the measures to be taken in pregnancy in terms of hygiene and legal and administrative requirements. This information should ideally be given before conception [13-15]. Information on how to avoid Toxoplasma infection could be cost-effectively added to messages on other health issues related to young adults (i.e. use of alcohol and drugs, sexually transmitted diseases). Any message promoting an early first serological test would indirectly be a benefit for other areas of antenatal care. Subsequent reminders that testing for toxoplasmosis should be extended to the date of delivery could also be used to convey other information on second or third trimester issues, such as breastfeeding.

Secondly, actions need to be tailored to those who prescribe the tests. In our study, first tests were performed earlier when prescribed by a GP, but subsequent tests were more regular when prescribed by an obstetrician-gynaecologist. As these findings contrast with previous evidence [12-13], further studies are necessary and will need to take into account the adherence of physicians and midwives to recommendations for toxoplasmosis screening, as well as their sex, location and social context, which have been found to play a role in relation to health education and prevention [16-17]. Meanwhile, there is a need to remind GPs, obstetricians and registered midwifes of their complementary roles [18]. The biologists performing the tests should also be encouraged to become involved and explain the importance of regular testing to professionals and patients.

The re-use of prescriptions had a positive impact on compliance. The principle of a single prescription covering the entire duration of pregnancy could be promoted as an easy measure. This could even be extended to other biological tests, appointments for medical visits or ultrasound examinations. 
Interestingly, the French antenatal prevention programme for toxoplasmosis illustrates well the long-term natural limitations of a programme not supported by a specific campaign. Potential decisions to reinforce it will need to be associated with measures to monitor their effectiveness, and necessary corrections will need to be introduced promptly. However, before taking steps to increase compliance, it is necessary to address the uncertainty surrounding the impact of preventive measures for congenital toxoplasmosis.

\section{Aknowledgements}

We thank Derek Byrne for proofreading the manuscript.

\section{References}

1. Remington JS, McLeod R, Thulliez P, Desmonts G. Toxoplasmosis. In: Remington JS, Klein J. Infectious Diseases of the Fetus and Newborn Infant, 5th ed, Philadelphia: WB Saunders; 2001. p. 205-346.

2. Wallon M, Kodjikian L, Binquet C, Garweg J, Fleury J, Quantin C, et al. Longterm ocular prognosis in 327 children with congenital toxoplasmosis. Pediatrics. 2004;113(6):1567-72.

3. Institut National de la Statistique et des Données Economiques (INSEE). État civil - Naissances et décès par commune, département et région, mariages par département et région. [Civil status - births and deaths by municipality, Département and region, marriages by Département and region]. Paris, France: INSEE. [In French]. Available from: http://www.insee.fr/fr/themes/ detail.asp?reg_id=99\&ref_id=etat-civil. [Accessed on February 4, 2009].

4. Berger F, Goulet V, Le Strat Y, Desenclos JC. Toxoplasmose chez les femmes enceintes en France: évolution de la séroprévalence et de l'incidence et facteurs associés, 1995-2003. [Toxoplasmosis in pregnant women in France: trends in seroprevalence and incidence, and associated factors, 1995-2003]. Bull Epidemiol Hebd. 2008;14-15:117-21. [ In French]. Available from: http:// www.invs.sante.fr/beh/2008/14_15/index.htm\#7_en

5. Blondel B, Supernant K, du Mazaubrun C, Breart G, editors. Enquête nationale périnatale 2003: situation en 2003 et évolution depuis 1998. [National perinatal survey 2003: situation in 2003 and development since 1998]. Paris: Ministère des Solidarité, de la santé et de la famille, and Lyon: Institut national de la santé et de la recherche médicale; 2005 Feb. [In French]. Available from http://www.sante.gouv.fr/htm/dossiers/perinat03/enquete.pdf

6. Leroy V, Raeber PA, Petersen E, Salmi LR, Kaminski M, Villena I, et al. National public health policies and routines programs to prevent congenital Toxoplasmosis, Europe, 2005. [Unpublished report]; Bordeaux, France: The Eurotoxo Group; 2005. Available from: http://eurotoxo.isped.u-bordeaux2.fr/ WWW_PUBLIC/DOC/EUROTOXO_R1_P3_European_national_policies_Dec2005.pdf

7. Carellos EV, Andrade GM, Aguiar RA. Avaliação da aplicação do protocolo de triagem pré-natal para toxoplasmose em Belo Horizonte, Minas Gerais, Brasil: estudo transversal em puérperas de duas maternidades. [Evaluation of prenatal screening for toxoplasmosis in Belo Horizonte, Minas Gerais State, Brazil: a cross-sectional study of postpartum women in two maternity hospitals]. Cad Saude Publica. 2008;24(2):391-401. [In Portuguese].

8. Eskild A, Oxman A, Magnus P, Bjørndal A, Bakketeig LS. Screening for toxoplasmosis in pregnancy: what is the evidence of reducing a health problem? J Med Screen. 1996;3(4):188-94.

9. Gollub EL, Leroy V, Gilbert R, Chêne G, Wallon M; the European Toxoprevention Study Group (EUROTOXO). Effectiveness of health education on Toxoplasmarelated knowledge, behaviour, and risk of seroconversion in pregnancy. Eur J Obstet Gynecol Reprod Biol. 2008;136(2):137-45.

10. SYROCOT (Systematic Review on Congenital Toxoplasmosis) study group; Thiébaut R, Leproust S, Chêne G, Gilbert R. Effectiveness of prenatal treatment for congenital toxoplasmosis: a meta-analysis of individual patients' data. Lancet. 2007;369(9556):115-22.

11. Wallon M, Mallaret MR, Mojon M, Peyron F. Evaluation de la politique de prévention de la toxoplasmose congénitale. [Congenital toxoplasmosis, evaluation of the prevention policy]. Presse Med. 1994;23(32):1467-70. [ In French].

12. Wallon M, Nguyen Hoang Hanh DT, Peyron F, Chêne G. Impact of health education for the primary prevention of Toxoplasma infection in pregnancy: lessons from the ERIS study.16th European Congress of Clinical Microbiology and Infectious Diseases (ECCMID); 2006 Apr 1-4; Nice (France). Abstract No: p876.
13. Haute Autorité de Santé (HAS). Comment mieux informer les femmes à risques. Des recommandations pour les professionnels de santé. [How to better inform the women at risk. Recommendations for health care professionals]. SaintDenis La Plaine, France: HAS; 2005 Apr. [In French]. Available from: http:// www.has-sante.fr/portail/upload/docs/application/pdf/femmes_enceintes recos.pdf

14. Johnson K, Posner SF, Biermann J, Cordero JF, Atrash HK, Parker CS, et al. Recommendations to improve preconception health and health care--United States. A report of the CDC/ATSDR Preconception Care Work Group and the Select Panel on Preconception Care. MMWR Recomm Rep. 2006;55(RR-6):1-23.

15. Ministère de la Santé, de la Jeunesse et des Sports. Présentation du Plan "Santé des jeunes". [Presentation of the plan "Health of the young"]. Press release; 2008 Feb 27. [In French]. Available from http://www.sante.gouv.fr/ accueil/plan_sante_jeunes.pdf

16. Abdel-Malek N, Chiarelli AM, Sloan M, Stewart DE, Mai V, Howlett RI. Influence of physician and patient characteristics on adherence to breast cancer screening recommendations. Eur J Cancer Prev. 2008;17(1):48-53

17. Lurie N, Slater J, McGovern P, Ekstrum J, Quam L, Margolis K. Preventive care for women. Does the sex of the physician matter? N Engl J Med. 1993;329(7):47882

18. Henderson JT, Weisman CS, Grason H. Are two doctors better than one? Women's physician use and appropriate care. Womens Health Issues. 2002;12(3):138-49.

This article was published on 5 March 2009.

Citation style for this article: Cornu C, Bissery A, Malbos C, Garwig R, Cocherel C, Ecochard R, Peyron F, Wallon M. Factors affecting the adherence to an antenatal screening programme: an experience with toxoplasmosis screening in France. Euro Surveill. 2009;14(9):pii=19137. Available online: http://www.eurosurveillance.org/ ViewArticle.aspx?ArticleId=19137 